\title{
Healthcare Associated Infection in the Neonatal Intensive Care Unit of King Abdl Aziz Specialist Hospital, Taif, KSA
}

\author{
A. K. Al-Zahrani ${ }^{1}$, E. M. Eed $^{2}$, A. A. Alsulaimani ${ }^{3}$, S. H. Abbadi ${ }^{4 *}$ \\ ${ }^{1}$ Department Pediatrics, College of Medicine Taif University, Neonatal Intensive Care Unit King Abdulaziz Specialist Hospital, Taif, \\ $\mathrm{KSA} ;{ }^{2}$ Department of Medical Microbiology and Immunology, Faculty of Medicine Menoufia University, Egypt and College of Ap- \\ plied Medical Sciences Taif University, Taif, KSA; ${ }^{3}$ Associate Prof. Medical College, Consultant Pediatrician \& Neonatologist, Taif \\ University, Taif, KSA; ${ }^{4}$ Department of Medical Microbiology and Immunology, Faculty of Medicine Suez Canal University, Egypt \\ and College of Medicine, Taif University, KSA. \\ Email: ${ }^{*}$ saidabbadi@tu.edu.sa
}

Received October $13^{\text {th }}, 2013$; revised November $13^{\text {th }}, 2013$; accepted November $20^{\text {th }}, 2013$

Copyright (C) 2013 A. K. Al-Zahrani et al. This is an open access article distributed under the Creative Commons Attribution License, which permits unrestricted use, distribution, and reproduction in any medium, provided the original work is properly cited.

\begin{abstract}
Healthcare-associated infection is a common problem of newborn in neonatal intensive care units. It results in high mortality rate and serious complications. The Aim: to assess the incidence, etiology and the mortality of healthcareassociated infections of patients in neonatal intensive care unit at King Abdl Aziz Specialist Hospital (KAASH), Taif, Kingdom of Saudi Arabia. Material and Methods: This is a retrospective study including 8033 neonates admitted to neonatal intensive care unit during period between April, 2006 and December, 2012. The health-care associated infection rate, mortality rate, causative organism and risk factors were studied. Results: The prevalence of health-care associated infection was found to be $6.03 \%$; the mortality rate was $27.1 \%$. The highest prevalence was among children with the birth weight below $1000 \mathrm{~g}$. The most frequent causative pathogen was klebseilla spp, followed by other gram negative bacilli. Conclusion: The rate of healthcare-associated infections in neonatal intensive care unit at KAASH was relatively high. In addition, the mortality rate was observed to be high $(27.1 \%)$ owing to the high virulence of the causative organisms.
\end{abstract}

Keywords: Healthcare-Associated Infection; Newborn; Neonatal Intensive Care Unit

\section{Introduction}

Health-care associated infections (HAIs) continue to be a major public health problem throughout the world, especially in the neonatal intensive care unit (NICU). Neonates in the NICU are a very vulnerable group due to defective immunity and the increasing number of technology dependant infants [1,2]. Deficiencies of both innate and adaptive immunity contribute to the impaired neonatal host defense [3]. A domination of naive immune cells, functional impairments and lower leukocyte subset numbers contribute further to an increased susceptibility $[4,5]$. The mode of infection transmission is mainly through the care-giver staff specially if the proper antiseptic measures are not considered [4]. Infection control for preventing nosocomial infections may play an important role in reducing medical costs, period of hospital stay, and mortality in hospitalized patients [6].

\footnotetext{
"Corresponding author.
}

Sepsis in the newborn is classified into early-onset form (EONS), within the first 72 hours of life, and lateonset form (LONS), which takes place afterwards (3). HAI in the NICU takes many forms, and the most frequent forms are the blood stream infection (septicemia) $(28 \%)$, ventilator associated pneumonia (21\%). Meningitis, gastro-enteritis, skin and eye infections are also common infections [7]. Many risk factors of HAI in the NICU are involved. The most important is excessive invasive procedures such as peripheral cannulation, central venous catheter placement, tracheal incubation and ventilation [6]. Furthermore, the duration of hospital stay, plays an important role; that is, the longer the stay, the higher the incidence of HAI [7]. Premature infants, with a birth weight less than $1000 \mathrm{~g}$ (ELBW: extremely low birth weight infants), are particularly predisposed to sepsis, as there is an inverse correlation between gestational age, birth weight, and sepsis $[8,9]$. Furthermore, the age of the neonate has a role in the incidence of HAI. Previous stu- 
dies have shown that the peak incidence of infection occurred between the age of $10^{\text {th }}$ and $20^{\text {th }}$ day [2].

Many organisms are involved in neonatal HAI, and the commonest are E. coli (36.6\%), Staphylococcusaureus (29.5\%), Pseudomonas spp (22.4\%), Klebsiella spp (7.6\%) and Proteus spp (3.8\%). St pneumoniae, enterococci and Serratia are also involved [10,11]. In spite of the high prevalence and severity of neonatal HAI, the hospital represents a well established reservoir for resistant organisms that makes the problem difficult to control, and neonatal HAI is still a preventable problem, as risk factors can potentially be employed to develop local strategy for prevention [12]. This could be achieved through strict antiseptic measures for environment, staff, equipment, and minimizing invasive procedures [13]. These perfect control measures require proper epidemiological studies and tracing of infection [14]. The principal method of diagnosing sepsis is the isolation of causative organisms from blood cultures and antimicrobial susceptibility testing $[15,16]$. Results are usually available between $48-72$ hours after specimen collection and therefore, initial antimicrobial treatment has been usually empirical with the aim that the most likely pathogens would be susceptible to the chosen drugs [15]. Therefore, this study was conducted in order to investigate the epidemiological characteristics of HAI in the aspects of infection rate, common pathogens and risk factors in our NICU in order to guide empirical therapy and improve better preventive measures.

\section{Subjects and Methods}

\subsection{Clinical Setting and Patients Population}

This is a retrospective, hospital-based study. It was carried out in the neonatal intensive care unit (NICU) at King Abdul Aziz Specialist Hospital (KAASH), Taif, Kingdom of Saudi Arabia during the period April 2006 December, 2012. KAASH is a 500-bed tertiary-level hospital. The NICU is a level III nursery with 60 bed capacity, dealing with all cases delivered in the hospital that ranges between 12,000 to 14,000 deliveries each year. Data were collected from the medical records in standardized collection sheets and included demographic data, birth weight, gestational age, gender, outcome, and delivery data (mode of delivery, maturity). The prevalence of sepsis was calculated by dividing the number of newborns with sepsis by the total number of newborns admitted to the NICU.

\subsection{Case Definition}

Health care associated sepsis, defined as a positive blood culture taken after 48 hours of admission to NICU with presence of clinical signs that are suggestive of neonatal septicemia [12].

\subsection{Culture and Susceptibility}

Each neonate showing manifestation of sepsis was subjected to sampling for blood culture, cerebrospinal fluid (CSF) culture, or other samples according the clinical presentation. Blood culture was done for all neonates who were suspected to have sepsis. All blood samples were collected from the peripheral vein under strict aseptic precautions, before starting antibiotic therapy. Blood culture samples were incubated in the BacT/ALERT 3D (bioMerieux, France), sub-cultures were done on blood agar, chocolate agar, Mannitol salt agar and Mac Conkey's agar plates (Oxoid) and incubated at $37^{\circ} \mathrm{C}$ for 24 48 hours. The bacterial isolates were identified by standard laboratory techniques, using standard culture media and biochemical reactions according to the Clinical Laboratory Standard Institute (CLSI) criteria. Thereafter, antibiotic susceptibility testing was performed on Muller Hinton agar (Oxoid) by Kirby-Bauer disk diffusion method and interpreted according to CLSI criteria [17]. Data were analyzed using SPSS software (Version 10.0; SPSS Inc., Chicago).

\section{Results}

Table 1 shows that during the study period (April, 2006December, 2012) the total number of the patients admitted to the neonatal intensive care unit were 8033 neonates. The total HAI rate in our ICU was $6.03 \%$. Being highest in year 2006 followed by year 2007. While was lowest in year 2008. There were a total 484 health care associated infections, of them 258 infant were males and 226 were females.

The studied newborn were categorized acceding to the birth weight into four groups group I (less than $1000 \mathrm{~g}$ ), group II $(1000-1500 \mathrm{~g})$, group III $(1501-2500 \mathrm{~g})$ and group IV (more than $2500 \mathrm{~g}$ ).

The results showed different HAI rate among four birth weight groups. The highest rate $(29.54 \%)$ was found in patients with weight below $1000 \mathrm{~g}$, and was $26.65 \%$ in group II, $28.7 \%$ in group III while, the HAI rate among the fourth group was only $14 \%$ (Table 2).

Also, the studied newborn were categorized acceding to the gestational age in weeks into four groups group I (less than $28 w)$, group II (28 $-31 \mathrm{w}+6$ days), group III (32 - $36 \mathrm{w}+6$ days) and group IV (equal or more than 37 w) (Table 2). During the study period, the most common recovered organism was klebseilla spp (128 isolates) followed by Enterobacter spp species, E. coli and Acinetobacterspp (79, 78 and 72 isolates respectively. Whereas gram positive cocci as CoNS, Staphylococcus aureus and Enterococcus were less frequent $(31,9$, and 7 isolates respectively) (Table 3 ). 
Table 1. Healthcare-associated infection (HAI) among those admitted to the neonatal intensive care unit at King Abdulaziz Specialist Hospital, Taif, Kigdom of Saudi Arabia during the period April 2006 - December 2012.

\begin{tabular}{cccc}
\hline Years & No. of Admissions in NICU & No. HAI & HAI Rate \\
\hline 2006 & 1006 & 155 & $15.4 \%$ \\
2007 & 959 & 79 & $8.2 \%$ \\
2008 & 970 & 11 & $1.14 \%$ \\
2009 & 1259 & 81 & $6.4 \%$ \\
2010 & 1254 & 73 & $5.8 \%$ \\
2011 & 1301 & 48 & $3.7 \%$ \\
2012 & 1284 & 37 & $2.9 \%$ \\
Total & $\mathbf{8 0 3 3}$ & $\mathbf{4 8 4}$ & $\mathbf{6 . 0 3} \%$ \\
\hline
\end{tabular}

Table 2. Characteristics of the $\mathbf{4 8 4}$ patients with health care associated infections among those admitted to the neonatal intensive care unit at King Abdulaziz Specialist Hospital, Taif, Kingdom of Saudi Arabia during the period April 2006 - December 2012.

\begin{tabular}{cccc}
\hline & Characteristic & $\begin{array}{c}\text { Number of } \\
\text { Patients }\end{array}$ & $\begin{array}{c}\text { Pateinets } \\
\text { Percent }\end{array}$ \\
\hline \multirow{2}{*}{ Gender } & Male & 258 & $53.3 \%$ \\
& Female & 226 & $46.7 \%$ \\
Birth & G I $(<1000)$ & 148 & $29.54 \%$ \\
weight & G II $(1000-1500)$ & 129 & $27.9 \%$ \\
& G III $(1501-2500)$ & 139 & $28.5 \%$ \\
Gestational & G II $(28-31+6)$ & 123 & $14 . \%$ \\
age & G III $(32-36+6)$ & 129 & $26.7 \%$ \\
& G IV $(\geq 37)$ & 81 & $25.4 \%$ \\
Discharge & Alive & 353 & $72.9 \%$ \\
status & Died & 131 & $27.1 \%$ \\
Total & & & \\
\hline
\end{tabular}

The most common organism associated with complication was klebseilla spp (128 total complication) whereas death was the most frequent complication where 131 case of death were reported. Resistance to amoxicillin was the highest as it was observed in $90 \%$ of Klebsiella and $81 \%$ of $E$. coli, whilst other Gram negative bacilli showed complete resistance to this drug. Klebsiella and $E$. coli also exhibited increased resistance to gentamycin (60\% and $57 \%$ respectively), as well as to Cipro-floxacin
Table 3. Distribution of causative pathogens HAI according to the year of the study among pateints admitted to the neonatal intensive care unit at King Abdulaziz Specialist Hospital, Taif, Kigdom of Saudi Arabia during the period April 2006 - December 2012.

\begin{tabular}{cccccccccc}
\hline \multirow{2}{*}{ Pathogen } & \multicolumn{7}{c}{ No. of Isolates (\%) } \\
\cline { 2 - 8 } & 2006 & 2007 & 2008 & 2009 & 2010 & 2011 & 2012 & Total \\
\hline $\begin{array}{c}\text { Escherichia coli } \\
\text { Enterobacter } \\
\text { species }\end{array}$ & 22 & 14 & 3 & 11 & 15 & 5 & 8 & 78 \\
$\begin{array}{c}\text { Klebsiella species } \\
\text { Acinetobacter }\end{array}$ & 28 & 8 & 1 & 21 & 31 & 28 & 11 & 128 \\
species & 36 & 21 & 3 & 3 & 4 & 0 & 5 & 72 \\
Pseudomonas & 5 & 4 & 2 & 9 & 1 & 3 & 3 & 27 \\
aeruginosa & & & & & & & & \\
Staphylococcus & 1 & 2 & 1 & 2 & 1 & 1 & 1 & 9 \\
aureus & 14 & 0 & 1 & 9 & 6 & 1 & 0 & 31 \\
CoNS & 4 & 0 & 0 & 2 & 0 & 1 & 0 & 7 \\
Enterococcus & & & & & & & & \\
Serratiamarcescens & 5 & 5 & 0 & 6 & 5 & 1 & 2 & 24 \\
$\begin{array}{c}\text { Group B } \\
\text { Streptococcus }\end{array}$ & 5 & 0 & 0 & 2 & 0 & 0 & 0 & 7 \\
$\begin{array}{c}\text { Candida albicans } \\
\text { Total }\end{array}$ & 10 & 2 & 0 & 5 & 1 & 3 & 1 & 22 \\
\hline
\end{tabular}

(45\%, $43 \%$ respectively). More than $50 \%$ of E. coli $(40 / 78)$ and $46 \%$ of Klebsiella species (59/128) were resistant to one or more third generation Cephalosporins. Other Gram negative bacilli (mostly Enterobacter species) also recorded high-level resistance to third-generation cephalosporins (75\%). Approximately one-third of Klebsiella species (42/128) and E. coli (26/78 were ESBL producers (Table 4).

\section{Discussion}

Health care associated infections in the NICU constitute a major health problem and may be associated with substantial morbidity and mortality. Those infections in neonates are life-threatening emergencies. Identification of the common bacteria causing such infections and their susceptibility patterns will provide necessary information for timely intervention [18]. In the present study, the collective HAI rate in our NICU over years 2006-2012 was $6.03 \%$. The highest rate was observed in $2006(15.4 \%)$ while the lowest rate in $2008(1.14 \%)$. The sudden drop in the infection rate in 2008 may be due to the strict infection control precaution taken after the exaggerated high rate in the previous years (more than 15\% in 2006) 
Table 4. Distribution of causative pathogens of HAI according to complications of sepsis among patients admitted to the neonatal intensive care unit at King Abdulaziz Specialist Hospital, Taif, Kingdom of Saudi Arabia during the period April 2006 - December 2012.

\begin{tabular}{cccccc}
\hline Pathogen & Ventilation & NEC & DIC & Death & Total \\
Escherichia coli & 32 & 5 & 20 & 20 & 78 \\
$\begin{array}{c}\text { Enterobacter } \\
\text { species }\end{array}$ & 23 & 8 & 15 & 18 & 79 \\
$\begin{array}{c}\text { Klebsiella species } \\
\text { Acinetobacter }\end{array}$ & 46 & 7 & 18 & 37 & 128 \\
$\quad 29$ & 2 & 22 & 20 & 72 \\
$\begin{array}{c}\text { species } \\
\text { Pseudomonas aeru- } \\
\text { ginosa }\end{array}$ & 6 & 2 & 7 & 10 & 27 \\
$\begin{array}{c}\text { Staphylococcus } \\
\text { aureus }\end{array}$ & 5 & 1 & 1 & 5 & 9 \\
$\quad$ CONS & 10 & 5 & 6 & 3 & 31 \\
$\begin{array}{c}\text { Enterococcus } \\
\text { Serratiamarcescens }\end{array}$ & 5 & 4 & 4 & 2 & 7 \\
$\quad 6$ & 4 & 5 & 9 & 24 \\
$\quad \begin{array}{l}\text { Group B } \\
\text { Streptococcus }\end{array}$ & 1 & 1 & 1 & 1 & 7 \\
Candida albicans & 7 & 5 & 4 & 6 & 22 \\
$\quad$ Total & 170 & 44 & 103 & 131 & 484 \\
\hline
\end{tabular}

but generally the infection rate had declined in our NICU (Table 2). The results of the present study are in agreement with previous study reported by Iwona et al., (2012) over the 6-year period, from 2005 to 2010 , in which 2610 neonates were hospitalized in NICU and HAI was $7.32 \%$ [19]. Furthermore, a retrospective study done in the neonatal intensive care unit of the Mexican institute in the period between 2004 and 2007, HAI was found $4.3 \%$ (514 out of 11,790 newborns) [20]. However, on the other hand, a similar study conducted in Nigeria estimated HAI rate in university of Port Harcourt Teaching Hospital was 34.2\%, [21,22]. Also in Korea, Jeong et al., [23] reported a HAI rate in NICU of $30.3 \%$ [24]. This variability in HAI rate depends besides infection control measure on many determinant factors such as the gestational age, birth weight distribution of the infants surveyed for the report, and on the specific environment and care practices, [23].

In the present study, HAI rate differs among four birth weight groups. The highest rate $(29.54 \%)$ was found in patients with weight below $1000 \mathrm{~g}$. However it was surprising that the HAI rate was the higher in group III $(1501-2500 \mathrm{~g})$ than in group II $(100-1500 \mathrm{~g})$ which was found to be $28.7 \%$ and $26.65 \%$ respectively, while, the HAI rate among the fourth group was only $14 \%$. With regards to the effect of gestational age on HAI in the present study was in line with that of birth weight (the highest in newborn less than 28 weeks), this may be related to fact that low birth weight and premature labor mostly occur in combination. The majority of investigators have indicated that the risk of developing HAI increased with lower birth weight. Stoll et al., [3] reported infection rates of $50 \%$ for infants weighting below $750 \mathrm{~g}$, $33 \%$ for those between 751 and $1000 \mathrm{~g}, 21 \%$ for those between 1001 and $1250 \mathrm{~g}$ and $10 \%$ for those between 1251 and $1500 \mathrm{~g}$ [3]. During the study period, the most common pathogen incriminated for health care-associated infection was klebseilla spp (128 isolates) followed by Enterobacter spp species, E coli and Acinetobacter spp (79, 78 and 72 isolates respectively), which means that Gram negative bacilli were the major causative pathogen in our NICU. The same findings were reported by Yilmaz et al., [25] where Klebsiella spp. And E. coli, together, were responsible for $67 \%$ of HAI occurred in NICU [25]. Many investigators concur with our study in reporting that Gram-negative rods as the most common etiological factors [26]. Whereas, Gaynes et al., [27] and Stoll et al., [3], differ as they found that co-agulase-negative staphylococci were the most common pathogen, presenting in $51 \%$ and $55 \%$ of cases, respectively $[3,27]$. The similar observation had Yelda et al., [20], they found that Gram-positive cocci account for $55.4 \%$ of HAI, and the most common organisms were Staphylococci [20].

Most of these isolates showed multiple antibiotics resistance. Results showed that approximately one-third of Klebsiella species (42/128) and E. coli (26/78) were ESBL producers .These results are in agreement with Dinesh et al., (2011) who described a widespread problem of ESBL-producing multidrug-resistant strains of Klebsiella and E. coli in hospital [28]. Also Amita et al., (2003) reported that more than $78 \%$ of Gram-negative isolates were positive in the screening test for ESBL production in blood borne neonatal infections [29].

The mortality rate was relatively high in the present study (27\%); since all fatality cases were associated with Gram-negative pathogens. Gram-negative HAI often presents with a more rapid clinical deterioration and is commonly associated with shock and coagulation problems. According to Makhoul et al., [30] mortality after Gramnegative sepsis $(26.2 \%)$ and Candida sepsis $(27.6 \%)$ is similar and significantly higher than with Gram-positive sepsis $(8.7 \%)$ [30]. Although other authors show that mortality caused by Gram positive pathogens is lower, about $2.83 \%$ to $6.98 \%$ [31]. However, organisms like co-agulase-negative Staphylococci may be underestimated because many cultures that grow Gram-positive bacteria represent skin contaminants rather than true blood stream infections. 


\section{Conclusion}

The overall HAI rate in our NICU over years 2006 2012 was relatively high although declining in the recent years due to application of strict infection control measures, and the most prevalent organism was klebseilla spp, followed by other gram negative bacilli which commonly associated with shock and coagulation problems. Therefore, these organisms are blamed for relatively high mortality rate.

\section{Acknowledgements}

I would like to express my sincere thanks and appreciation to the microbiology laboratory members in King Abdel Aziz Specialized Hospital (KAASH) for their support to complete of this research.

\section{REFERENCES}

[1] E. B. Daynia, N. Trusha, S. Charlotte and A. C. Peter, "Bacterial Bloodstream Infections in Neonates in a Developing Country," ISRN Pediatrics, 2012, pp. 508-512.

[2] N. Zafar, C. M. Wallace, P. Kieffer and P. Schroeder, "Improving Survival of Vulnerable Infant Increases Neonatal. Intensive Care Unit Nosocomial Infection Rate," Archives of Pediatrics \& Adolescent Medicine, Vol. 155, No. 10, 2001, p. 1098. http://dx.doi.org/10.1001/archpedi.155.10.1098

[3] B. J. Stoll, N. Hansen, A. Fanaroff, L. Wright, W. Carlo and E. Dnovan, "Late-Onset Sepsis in Very Low Birth Weight Neonates: The Experience of the NICHD Neonatal Research Network," Pediatric NLM MEDLINE, Vol. 110, No. 2, 2002, pp. 285-286.

http://dx.doi.org/10.1542/peds.110.2.285

[4] E. Hotoura, V. Giapros, A. Kostoula, P. Spirou and S. Andronikou, "Tracking Changes of Lymphocyte Subsets and Pre-Inflammatory Mediators in Full-Term Neonates with Suspected or Documented Infection," Scandinavian Journal of Immunity, Vol. 73, No. 3, 2011, pp. 250-255. http://dx.doi.org/10.1111/j.1365-3083.2010.02499.x

[5] S. K. Iwona, J. Aldona and K. Andrzej, "Healthcare-Associated Infections in a Neonatal Intensive Care Unit," Archives of Medical Science, Vol. 8, No. 5, 2012, pp. 854-858.

[6] W. H. Sheng, W. C. Chie, Y. C. Chen, C. C. Hung, J. T. Wang and S. C. Chang, "Impact of Nosocomial Infections on Medical Costs, Hospital Stay, and Outcome in Hospitalized Patients," Journal of the Formosan Medical Association, Vol. 104, No. 5, 2005, pp. 318-326.

[7] J. S. Yogaraj and A. M. Elward, "Risk Factors and Outcome of Nosocomial Bloodstream Infection in Neonatal ICU. Washington University, School of Medicine, USA," Pediatrics, Vol. 110, No. 3, 2000, pp. 481-485. http://dx.doi.org/10.1542/peds.110.3.481

[8] A. Jaiswal, S. Murki, P. Gaddam and A. Reddy, "Early Neonatal Morbidities in Late Preterm Infants," Indian Pediatrics, Vol. 48, No. 8, 2011, pp. 607-611.

\section{http://dx.doi.org/10.1007/s13312-011-0105-y}

[9] V. G. Hemming, J. C. Overall and M. R. Britt, "Nosocomial Infection in a Newborn Intensive Care Unit," Infection Control and Hospital Epidemiology, Vol. 21, No. 2, 2000, pp. 80-87.

[10] A. P. Richard and M. R. Tara, "Biomarkers for Late-Onset Neonatal Sepsis," Genome Medicine, Vol. 2, No. 9, 2010, 2010, pp. 58-60. http://dx.doi.org/10.1186/gm179

[11] T. B. Hyde, T. M. Hilger, A. Reingold, M. M. Farley, K. L. O'Brien and A. Schuchat, "Trends in Incidence and Antimicrobial Resistance of Early-Onset Sepsis: Population-Based Surveillance in San Francisco and Atlanta," Pediatrics, Vol. 110, No. 4, 2002, pp. 690-695. http://dx.doi.org/10.1542/peds.110.4.690

[12] J. N. Baptiste, K. D. Benjamin, M. C. Wolkowiez, V. G. Fowler, M. Laughon and P. B. Smith, "Coagulase-Negative Staphylococcal Infections in the Neonatal Intensive Care Unit," Infection Control and Hospital Epidemiology, Vol. 32, No. 7, 2012, pp. 679-686. http://dx.doi.org/10.1086/660361

[13] T. Horan, M. Andrus and A. Dudeck, "Surveillance Definition of Health Care Associated Infection and Criteria for Specific Types of Infections in the Acute Care Setting," American Journal of Infection Control, Vol. 36, 2008, pp. 309-332.| http://dx.doi.org/10.1016/j.ajic.2008.03.002

[14] H. Vishal, S. Marcel, H. Wil, O. Alewijn, G. Ronald, W. Peter and F. K. René, "Coagulase-Negative Staphylococcal Skin Carriage among Neonatal Intensive Care Unit Personnel: From Population to Infection," Journal of Clinical Microbiology, Vol. 48, No. 11, 2010, pp. 3876-3879. http://dx.doi.org/10.1128/JCM.00967-10

[15] E. K. Samuel, Q. Lawrence, S. Kenneth, B. Z. Juventus, I. B. Patricia and A. A. Anthony, "Susceptibility of Bacterial Etiological Agents to Commonly-Used Antimicrobial Agents in Children with Sepsis at the Tamale Teaching Hospital," BMC Infectious Disease, Vol. 13, 2013, pp. 89-91. http://dx.doi.org/10.1186/1471-2334-13-89

[16] K. C. Iregbu, O. Y. Elegba and I. B. Babaniyi, "Bacteriological Profile of Neonatal Septicaemia in a Tertiary Hospital in Nigeria," African Health Science, Vol. 6, No. 3, 2006, pp. 151-153.

[17] M. L. Wilson, M. Mitchell and A. J. Morris, "Principles and Producers for Blood Culture; Approved Guidelines," CLSI, 2007, pp. 7-10.

[18] D. C. Kasper, I. Altiok, T. P. Mechtler, J. Böhm, J. Straub, Langgartner, et al., "Molecular Detection of Late-Onset Neonatal Sepsis in Premature Infants Using Small Blood Volumes: Proof-of-Concept," Neonatology, Vol. 103, No. 4, 2013, pp. 268-273. http://dx.doi.org/10.1159/000346365

[19] S. K. Iwona and K. Piotr, "Healthcare-Associated Bloodstream Infection in Neonatal Intensive Care Unit," Archives of Perinatal Medicine, Vol. 15, No. 1, 2009, pp. 26-30.

[20] A. L. Yelda, A. N. José, R. V. Juan, R. Q. Ulises, D. R. Nidia, P. B. Etna, et al., "Risk Factors and Prognosis for Neonatal Sepsis in Southeastern Mexico: Analysis of a Four- 
Year Historic Cohort Follow-Up," BMC Pregnancy and Childbirth, Vol. 12, 2012, pp. 48-49. http://dx.doi.org/10.1186/1471-2393-12-48

[21] M. M. Meremikwu, C. E. Nwachukwu, A. E. Asuquo, J. U. Okebe and S. J. Utsalo, "Bacterial Isolates from Blood Cultures of Children with Suspected Septicemia in Calabar, Nigeria," BMC Infectious Diseases, Vol. 5, 2005, pp. 110-114. http://dx.doi.org/10.1186/1471-2334-5-110

[22] A. A. Adedokun, N. Frank-Peterside, I. J. Awah, O. K. Obunge and G. S. Omakwele, "Incidence of Septicemia in Children Attending the University of Port Harcourt Teaching Hospital, Port Harcourt South-South Nigeria," International Science and Investment Journal, Vol. 23, 2012, pp. 106-110.

[23] S. Nambiar, "Change in Epidemiology of Health-Care Associated Infections in Neonatal Intensive Care Unit," The Pediatric Infectious Disease Journal, Vol. 21, 2002, pp. 310-312. http://dx.doi.org/10.1097/00006454-200209000-00011

[24] S. S. Jeong, J. S. Jeong and E. O. Choi, "Nosocomial Infection in a Newborn Intensive Care Unit (NICU), South Korea," BMC Infectious Diseases, Vol. 6, 2006, pp. 103108. http://dx.doi.org/10.1186/1471-2334-6-103

[25] N. O. Yilmaz, N. Agus, M. Helvaci, S. Kose, E. Ozer and Z. Sahbudak, "Change in Pathogens Causing Late-Onset Sepsis in Neonatal Intensive Care Unit in Izmir, Turkey," Iranian Journal of Pediatrics, Vol. 20, No. 4, 2010, pp. 451-457.

[26] A. Jurczak, A. Kordek and E. Grochans, "Clinical and Mi- crobiological Characteristics of Hospital Infections in the Neonatal Intensive Care Unit," Advances in Medical Sciences, Vol. 52, No. 1, 2007, pp. 30-33.

[27] R. P. Gaynes, J. R. Edwards and W. R. Jarvis, "Nosocomial Infections among Neonates in High-Risk Nurseries in the United States," Pediatrics, Vol. 98, 1996, pp. 357-360.

[28] S. C. Dinesh, A. J. Judith, C. Rama, S. Nidhi, S. Nandita, P. Sailajanandan and R. M. Pravas, "Extended-Spectrum b-Lactamase-Producing Gram-Negative Bacteria Causing Neonatal Sepsis in India in Rural and Urban Settings," Journal of Medical Microbiology, Vol. 60, 2011, pp. 500507. http://dx.doi.org/10.1099/jmm.0.027375-0

[29] J. Amita, R. Indranil, K. G. Mahendra, K. Mala and S. K. Agarwal, "Prevalence of Extended-Spectrum Beta Lactamase Producing Gram-Negative Bacteria in Septicaemicneonates in a Tertiary Care Hospital," Journal of Medical Microbiology, Vol. 52, 2003, pp. 421-424. http://dx.doi.org/10.1099/jmm.0.04966-0

[30] I. R. Makhoul, P. Sujov and T. Smolkin, "Epidemiological, Clinical, and Microbiological Characteristics of LateOnset Sepsis among Very Low Birth Weight Infants in Israel: A National Survey," Pediatrics, Vol. 109, 2002, pp. 34-35. http://dx.doi.org/10.1542/peds.109.1.34

[31] B. J. Stoll, N. Hansen and A. Fanaroff, "Changes in Pathogens Causing Early Onset Sepsis in Very Low Birth Weight Infants," The New England Journal of Medicine, Vol. 347, 2002, pp. 240-247. http://dx.doi.org/10.1056/NEJMoa012657 